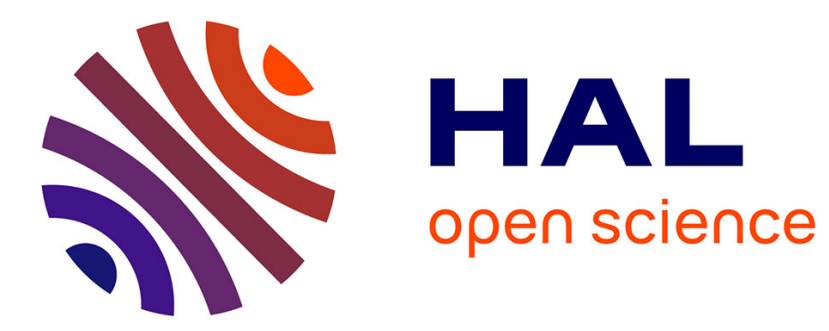

\title{
The sticking probability of D2O-water on ice: Isotope effects and the influence of vibrational excitation
}

\author{
P. Morten Hundt, Régis Bisson, Rainer D. Beck
}

\section{To cite this version:}

P. Morten Hundt, Régis Bisson, Rainer D. Beck. The sticking probability of D2O-water on ice: Isotope effects and the influence of vibrational excitation. Journal of Chemical Physics, 2012, 137, pp.074701. 10.1063/1.4742914 . hal-00834749

\section{HAL Id: hal-00834749 \\ https://hal.science/hal-00834749}

Submitted on 25 Nov 2015

HAL is a multi-disciplinary open access archive for the deposit and dissemination of scientific research documents, whether they are published or not. The documents may come from teaching and research institutions in France or abroad, or from public or private research centers.
L'archive ouverte pluridisciplinaire HAL, est destinée au dépôt et à la diffusion de documents scientifiques de niveau recherche, publiés ou non, émanant des établissements d'enseignement et de recherche français ou étrangers, des laboratoires publics ou privés. 


\title{
The sticking probability of $\mathrm{D}_{2} \mathrm{O}$-water on ice: Isotope effects and the influence of vibrational excitation
}

\author{
P. Morten Hundt, ${ }^{1}$ Régis Bisson, ${ }^{2}$ and Rainer D. Beck ${ }^{1, a)}$ \\ ${ }^{1}$ Laboratoire de Chimie Physique Moléculaire, Ecole Polytechnique Fédérale de Lausanne, \\ 1015 Lausanne, Switzerland \\ ${ }^{2}$ Aix-Marseille Université, PIIM, CNRS, UMR 7345, 13397 Marseille, France
}

(Received 29 May 2012; accepted 23 July 2012; published online 15 August 2012)

\begin{abstract}
The present study measures the sticking probability of heavy water $\left(\mathrm{D}_{2} \mathrm{O}\right)$ on $\mathrm{H}_{2} \mathrm{O}$ - and on $\mathrm{D}_{2} \mathrm{O}$-ice and probes the influence of selective OD-stretch excitation on $\mathrm{D}_{2} \mathrm{O}$ sticking on these ices. Molecular beam techniques are combined with infrared laser excitation to allow for precise control of incident angle, translational energy, and vibrational state of the incident molecules. For a translational energy of $69 \mathrm{~kJ} / \mathrm{mol}$ and large incident angles $\left(\theta \geq 45^{\circ}\right)$, the sticking probability of $\mathrm{D}_{2} \mathrm{O}$ on $\mathrm{H}_{2} \mathrm{O}$-ice was found to be $1 \%$ lower than on $\mathrm{D}_{2} \mathrm{O}$-ice. OD-stretch excitation by IR laser pumping of the incident $\mathrm{D}_{2} \mathrm{O}$ molecules produces no detectable change of the $\mathrm{D}_{2} \mathrm{O}$ sticking probability $\left(<10^{-3}\right)$. The results are compared with other gas/surface systems for which the effect of vibrational excitation on trapping has been probed experimentally. () 2012 American Institute of Physics. [http://dx.doi.org/10.1063/1.4742914]
\end{abstract}

\section{INTRODUCTION}

The interaction of water with solid surfaces plays a fundamental role in many industrial and natural processes. Examples are catalysis, corrosion, and electrochemistry but also atmospheric chemistry and astrophysics. The physisorption probability of water on ice is a key parameter in the modeling of polar stratospheric cloud formation. ${ }^{1}$ Additionally, adsorption of water molecules is of relevance to the growth of ice on interstellar dust grains. ${ }^{2,3}$ The ice on these grains forms an important diagnostics of circumstellar environments of evolved stars since it can be identified by its infrared features and contains information about the physical conditions in the envelope.

In this study, the sticking probability of $\mathrm{D}_{2} \mathrm{O}$ on $\mathrm{H}_{2} \mathrm{O}$ ice and on $\mathrm{D}_{2} \mathrm{O}$-ice is investigated using state-selective vibrational excitation of the incident water molecules by laser radiation in a molecular beam. The molecular beam allows for precise control of speed and incident angle of the molecules impinging on the surface and the infrared laser pumping prepares a fraction of the beam in a selected ro-vibrational eigenstate with one quantum of OD-stretch vibration. Previous molecular beam studies have investigated the sticking of $\mathrm{H}_{2} \mathrm{O}$ on $\mathrm{H}_{2} \mathrm{O}$-ice ${ }^{4,5}$ and $\mathrm{D}_{2} \mathrm{O}$ on $\mathrm{D}_{2} \mathrm{O}$-ice ${ }^{6}$ but without selective vibrational state preparation. Sticking probabilities were found to be close to unity for small incident angles over a wide range of incident speed but decrease with increasing velocity component parallel to the surface. ${ }^{4}$ To our knowledge no data is available on isotope effects and the influence of vibrational excitation on the sticking probability of water on ice. The present study explores these questions in order to increase our understanding of the dynamics of water sticking on ice.

\footnotetext{
a) Author to whom correspondence should be addressed. Electronic mail: rainer.beck@epfl.ch.
}

\section{EXPERIMENTAL}

Experiments were performed in an ultra high vacuum (UHV) surface science/molecular beam apparatus (base pressure $10^{-10} \mathrm{mbar}$ ), designed to investigate interactions of laser excited molecules with solid surfaces. ${ }^{7-9}$ This section gives a brief summary of the most relevant features of the machine and the modifications made for the present study.

The molecular beam of water is generated by bubbling $\mathrm{He}$ gas at 2.0 bar through a reservoir containing $\mathrm{D}_{2} \mathrm{O}$ (obtained from Sigma-Aldrich with $99.9 \%$ isotopic purity) kept at $273 \mathrm{~K}$ for a vapor pressure of 5 mbar. ${ }^{10}$ The resulting $0.25 \%$ $\mathrm{D}_{2} \mathrm{O}$ in $\mathrm{He}$ mixture undergoes a continuous supersonic expansion through a temperature controlled nozzle with an orifice of $50 \mu \mathrm{m}$ diameter. The gas line between $\mathrm{D}_{2} \mathrm{O}$ reservoir and nozzle is heated to prevent condensation whereas the water reservoir can be cooled below room temperature in order to reduce the seed ratio of water in the molecular beam. A molecular beam is extracted from the supersonic expansion in the source chamber by a nickel skimmer (Beam Dynamics) and transmitted via two differential pumping stages before entering the UHV chamber through an aperture of $2 \mathrm{~mm}$ diameter. A quadrupole mass spectrometer (QMS) is mounted in the UHV chamber in line-of-sight of the molecular beam to measure its speed distribution by a time-of-flight technique in combination with a $200 \mathrm{~Hz}$ chopper wheel located in the second differential pumping stage. For the experiments presented here, nozzle temperatures of $373 \mathrm{~K}$ and $673 \mathrm{~K}$ where used resulting in average translational energies for $\mathrm{D}_{2} \mathrm{O}$ of $38 \mathrm{~kJ} / \mathrm{mol}$ and $69 \mathrm{~kJ} / \mathrm{mol}$ with a FWHM of the translational energy distributions of $6 \mathrm{~kJ} / \mathrm{mol}$ and $17 \mathrm{~kJ} / \mathrm{mol}$, respectively. From the vibrational energy level structure of $\mathrm{D}_{2} \mathrm{O},{ }^{11}$ the thermal vibrational energy content is calculated to be $1.4 \mathrm{~kJ} / \mathrm{mol}$ for a nozzle temperature of $673 \mathrm{~K}$ which is negligible compared to the incident translational energy of 38 and $69 \mathrm{~kJ} / \mathrm{mol}$ and $34 \mathrm{~kJ} / \mathrm{mol}$ of state specific OD-stretch vibrational energy. 
The QMS is also used to measure sticking probabilities of $\mathrm{D}_{2} \mathrm{O}$ on ice by the King and Wells beam reflection technique (K\&W hereafter). ${ }^{12}$ For this study, we employed two different molecular beam skimmer sizes: $1 \mathrm{~mm}$ and $0.5 \mathrm{~mm}$. The skimmer with $1 \mathrm{~mm}$ diameter orifice was used to generate an intense molecular beam in order to achieve maximal QMS signal to noise ratio for the $\mathrm{K} \& \mathrm{~W}$ measurements. However, we noticed a systematic error of $0.7 \%$ in the sticking probability measured by the $\mathrm{K} \& \mathrm{~W}$ method with the $1 \mathrm{~mm}$ skimmer due to scattering of a small fraction of the $\mathrm{D}_{2} \mathrm{O}$ beam by the $2 \mathrm{~mm}$ diameter entrance aperture of the UHV chamber. Apparently some $\mathrm{D}_{2} \mathrm{O}$ molecules could enter the UHV chamber and be detected by the QMS without ever colliding with the cold target surface. For this reason, the highest sticking probability measured with the $1 \mathrm{~mm}$ skimmer was 0.993 instead of 1 . This systematic error could be eliminated at the cost of lower QMS S/N ratio by installing a $0.5 \mathrm{~mm}$ diameter skimmer in the source chamber, which reduced the molecular beam diameter to avoid scattering at the entrance aperture.

Quantum state specific ro-vibrational excitation of the incident molecular beam was achieved by optical pumping using a high power continuous-wave infrared optical parametric oscillator (cw IR-OPO, Argos model 2400, Lockheed Martin Aculight Corp.) The OPO idler wave is tunable from 2550 $3100 \mathrm{~cm}^{-1}$ with an output power up to $1 \mathrm{~W}$. The IR beam was focused by a cylindrical lens $(f=+250 \mathrm{~mm}$ ) in the molecular beam direction to form a $1.4 \times 3 \mathrm{~mm}$ interaction region with the molecular beam located $18 \mathrm{~mm}$ from the target surface. Doppler tuning resulting from the passage of the $\mathrm{D}_{2} \mathrm{O}$ beam through the curved wavefronts of the focused IR field generates a suitable frequency chirp to produce complete vibrational population transfer by rapid adiabatic passage. ${ }^{13}$ Resonance with a specific ro-vibrational transition is maintained through the deposition experiment by frequency locking of the OPO idler to a Lamb-dip (Doppler free saturation hole) in the Doppler broadened $\mathrm{D}_{2} \mathrm{O}$ absorption line detected in a static gas cell held at room temperature. ${ }^{9}$

The vibrationally excited $\mathrm{D}_{2} \mathrm{O}$ molecules in the molecular beam were detected by a pyroelectric detector that could be moved to intercept the molecular beam in the UHV chamber. Since the pyroelectric detector element is sensitive only to temperature changes, it can be used to selectively measure the vibrational energy content of the molecular beam when the IR beam is suitably modulated. To quantify the rotational level populations of $\mathrm{D}_{2} \mathrm{O}$ in the molecular beam, we record the IR power dependence of the pyroelectric detector signal for excitation from the five lowest rotational levels (Figure 1(b)) for a nozzle temperature of $373 \mathrm{~K}$. The asymptotic value of the pyroelectric detector signal at high IR power is proportional to rotational level population and independent of the transition dipole moment and can therefore be used to monitor the relative $\mathrm{D}_{2} \mathrm{O}$ rotational level population. Comparison of asymptotic detector signals with the calculated rotational level population as a function of rotational temperature (Figure 1(a)) indicates a rotational temperature of $12 \pm 1 \mathrm{~K}$. Under these conditions, the most populated rotational level is $1_{11}\left(\mathrm{~J}_{\mathrm{KaKc}}\right)$, with an asymptote of $144 \mathrm{mV}$ which corresponds to $30 \%$ of the total population of the first five levels. Since the power dependence for excitation of the $\mathrm{R}_{11}(1)$ transition
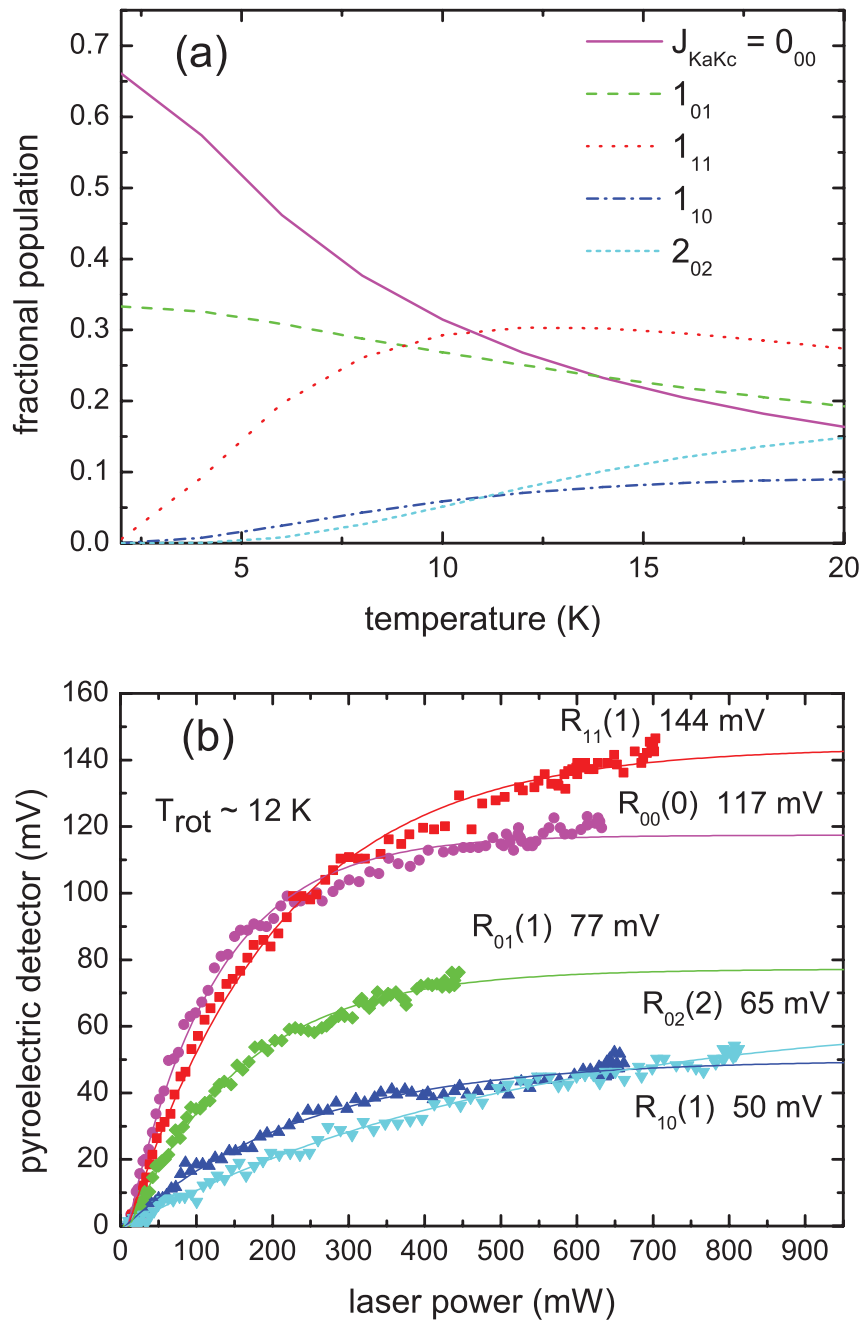

FIG. 1. Panel (a): Calculated fractional population of the five lowest rotational levels of $\mathrm{D}_{2} \mathrm{O}$ as function of rotational temperature. Close to $\mathrm{T}_{\text {rot }}$ $=0 \mathrm{~K}$, only the lowest rotational state of each of the two nuclear spin isomers (ortho and para) is populated in a 2:1 ortho:para ratio. Panel (b): Pyroelectric detector signal as function of excitation laser power monitoring the initial population of specific $\mathrm{J}_{\mathrm{KaKc}}$-levels in a $1 \% \mathrm{D}_{2} \mathrm{O}$ in He expansion for $\mathrm{T}_{\mathrm{N}}=373 \mathrm{~K}$. Each asymptote $\mathrm{A}$ of the power dependences (obtained from a fit of $y=A\left(1-e^{-k(x-x c)}\right)$ to the data) represents the population in the initial level of the indicated transition. Comparison of the two graphs yields a maximal excited fraction of $30 \%$ for the $\mathrm{R}_{11}(1)$ transition.

does not quite reach the asymptote (Figure 1(b)), we estimate that the IR pumping on this transition excites up to $25 \%$ of the $\mathrm{D}_{2} \mathrm{O}$ in the molecular beam to the first excited state of the $v_{3}$ antisymmetric OD-stretch normal mode vibration at $2808.76 \mathrm{~cm}^{-1}$.

A Ni(111) single-crystal sample with $10 \mathrm{~mm}$ diameter is mounted on a four-axis manipulator in the center of the UHV chamber. The Ni sample can be cooled to $100 \mathrm{~K}$ by flowing liquid nitrogen through the sample mount and heated up to $1200 \mathrm{~K}$ by electron impact from the backside for annealing. The Ni(111) surface is cleaned by $\mathrm{Ar}^{+}$sputtering followed by annealing to $1000 \mathrm{~K} . \mathrm{H}_{2} \mathrm{O}$-ice surfaces are prepared exposing the cold $\mathrm{Ni}(111)$ surface $\left(\mathrm{T}_{\mathrm{s}}=100 \mathrm{~K}\right)$ to 200 Langmuir of $\mathrm{H}_{2} \mathrm{O}$ vapor. Since ice is known to grow layer by layer on $\mathrm{Ni}(111),{ }^{14}$ we expect the formation of a homogeneous amorphous ice surface. The temperature programmed desorption 


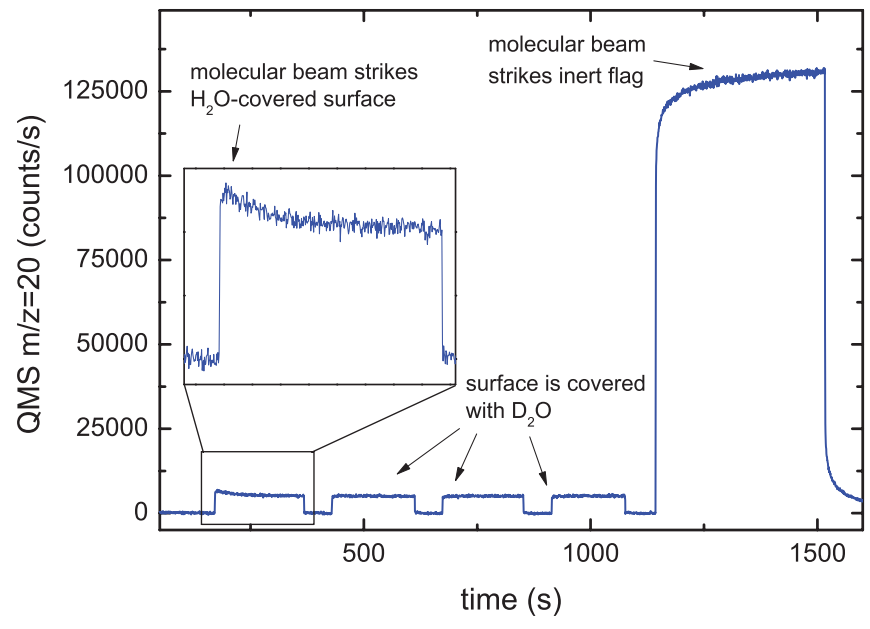

FIG. 2. $\mathrm{D}_{2} \mathrm{O}$ partial pressure changes in $\mathrm{UHV}$ chamber when a $\mathrm{H}_{2} \mathrm{O}$ or $\mathrm{D}_{2} \mathrm{O}$ ice surface is exposed to a $\mathrm{D}_{2} \mathrm{O}$ molecular beam $\left(\mathrm{E}_{\mathrm{t}}=69 \mathrm{~kJ} / \mathrm{mol}, \theta=60^{\circ}\right.$, $\mathrm{T}_{\mathrm{S}}=108 \mathrm{~K}$ ) in comparison to $\mathrm{D}_{2} \mathrm{O}$ scattering from an inert PTFE beam flag. Initially, when the $\mathrm{D}_{2} \mathrm{O}$ beam strikes with $\mathrm{H}_{2} \mathrm{O}$ surface, a larger pressure rise is detected (see insert) than for the three subsequent exposures when the ice surface is covered with $\mathrm{D}_{2} \mathrm{O}$-ice. For the final exposure, the $\mathrm{D}_{2} \mathrm{O}$ beam is scattered off an inert flag ( $0 \%$ sticking) instead off the ice surface.

profile of such a film (not shown here) includes a shoulder at $\mathrm{T}_{\mathrm{S}}=152 \mathrm{~K}$ which can be assigned to crystallization. ${ }^{15}$ After preparation, the $\mathrm{H}_{2} \mathrm{O}$-ice layer is exposed to the molecular beam of $\mathrm{D}_{2} \mathrm{O}$ at a given angle of incidence to study the sticking of $\mathrm{D}_{2} \mathrm{O}$ on $\mathrm{H}_{2} \mathrm{O}$-ice by the $\mathrm{K} \& \mathrm{~W}$ method. With an incident water flux of $3 \times 10^{12}$ molecules/s (estimated from the pressure rise in the UHV chamber when the molecular beam strikes an inert flag at room temperature) and a $4 \mathrm{~mm}$ molecular beam diameter at the surface, it takes about 45 seconds to deposit a monolayer of $\mathrm{D}_{2} \mathrm{O}$ on the $\mathrm{H}_{2} \mathrm{O}$ ice assuming a water monolayer density of $1.06 \times 10^{15}$ molecules $/ \mathrm{cm}^{2}$. . To obtain the sticking probability of $\mathrm{D}_{2} \mathrm{O}$ on $\mathrm{H}_{2} \mathrm{O}$-ice, we analyze only the first 5 seconds of the QMS trace during which less than $11 \%$ of a $\mathrm{D}_{2} \mathrm{O}$ monolayer is deposited on the $\mathrm{H}_{2} \mathrm{O}$-ice. After several minutes of molecular beam exposure, many layers of $\mathrm{D}_{2} \mathrm{O}$ have frozen on the initial $\mathrm{H}_{2} \mathrm{O}$-ice surface. This allows for the consecutive measurement of the sticking probabilities of $\mathrm{D}_{2} \mathrm{O}$ on $\mathrm{H}_{2} \mathrm{O}$-ice followed by $\mathrm{D}_{2} \mathrm{O}$ on $\mathrm{D}_{2} \mathrm{O}$-ice, as shown by a typical QMS trace in Figure 2.

\section{RESULTS AND DISCUSSION}

\section{A. Isotope effect in ground state $(v=0)$ sticking}

Figure 3 presents the vibrational ground state sticking probability of $\mathrm{D}_{2} \mathrm{O}$ on $\mathrm{H}_{2} \mathrm{O}$-ice and on $\mathrm{D}_{2} \mathrm{O}$-ice as a function of angle of incidence $\theta$ for two different incident translational energies $E_{t}=38$ and $69 \mathrm{~kJ} / \mathrm{mol}$. At $E_{t}=38 \mathrm{~kJ} / \mathrm{mol}$, the sticking probability on $\mathrm{D}_{2} \mathrm{O}$-ice is near unity $(0.99-0.995)$ for the whole range of incident angles in agreement with results reported by Gibson et al. ${ }^{6}$ In contrast, at $\mathrm{E}_{\mathrm{t}}=69 \mathrm{~kJ} / \mathrm{mol}$, a decrease in sticking is observed with increasing incident angle $\theta$ for $\theta \geq 45^{\circ}$. A similar effect was observed for the sticking of $\mathrm{H}_{2} \mathrm{O}$ on $\mathrm{H}_{2} \mathrm{O}$-ice by Batista et al. ${ }^{4}$ and explained to be due to the increasing velocity component parallel to the surface with increasing angle of incidence. It was suggested



FIG. 3. Ground state sticking probabilities of $\mathrm{D}_{2} \mathrm{O}$ on $\mathrm{H}_{2} \mathrm{O}-$ and $\mathrm{D}_{2} \mathrm{O}$-ice as function of incident angle for $\mathrm{E}_{\mathrm{t}}=38 \mathrm{~kJ} / \mathrm{mol}$ and $69 \mathrm{~kJ} / \mathrm{mol}$. The $\mathrm{D}_{2} \mathrm{O}$ sticking probability decreases with increasing speed parallel to the surface. $\mathrm{D}_{2} \mathrm{O}$ trapping on $\mathrm{H}_{2} \mathrm{O}$-ice is slightly $(1 \%)$ lower than on $\mathrm{D}_{2} \mathrm{O}$-ice. The error-bars indicate the standard deviation of at least three independent measurements.

that at high parallel velocity, the incident water molecules do not have sufficient time to reorient into a favorable orientation for adsorption on the two stable adsorption sites (A and B sites). Simulations by Batista et al. showed that $\mathrm{H}_{2} \mathrm{O}$ fits best on an $\mathrm{A}$ site if both hydrogen atoms point towards the surface whereas on a B site only one $\mathrm{H}$-atom points towards the surface and the other away from the surface. If the speed of the molecule parallel to the surface is greater than about $1000 \mathrm{~m} / \mathrm{s}$, the incident molecules do not have sufficient time to reorient according to the changing potentials of $\mathrm{A}$ and $\mathrm{B}$ sites leading to the observed reduction in sticking probability.

The comparison of the data shown in Figure 3 suggests a higher sticking coefficient for $\mathrm{D}_{2} \mathrm{O}$ on $\mathrm{D}_{2} \mathrm{O}$-ice than for $\mathrm{D}_{2} \mathrm{O}$ on $\mathrm{H}_{2} \mathrm{O}$-ice particularly at high incident translational energy and incident angle $\theta>45^{\circ}$. This isotope effect is also visible in Figure 2, which shows a typical result of a $\mathrm{K} \& \mathrm{~W}$ experiment that measures consecutively the sticking of $\mathrm{D}_{2} \mathrm{O}$ on $\mathrm{H}_{2} \mathrm{O}$-ice followed by $\mathrm{D}_{2} \mathrm{O}$ on $\mathrm{D}_{2} \mathrm{O}$-ice. Initially, when the molecular beam strikes the clean $\mathrm{H}_{2} \mathrm{O}$-ice surface, one can see a sharp rise in the $\mathrm{D}_{2} \mathrm{O}$-partial pressure followed by a slow decay towards lower constant $\mathrm{D}_{2} \mathrm{O}$-partial pressure (Figure 2: insert). Just after the sharp rise, the $\mathrm{D}_{2} \mathrm{O}$ partial pressure quantifies the fraction of $\mathrm{D}_{2} \mathrm{O}$ molecules, which do not stick but scatter from the $\mathrm{H}_{2} \mathrm{O}$-ice. The final lower $\mathrm{D}_{2} \mathrm{O}$-partial pressure corresponds to the fraction of $\mathrm{D}_{2} \mathrm{O}$ molecules scattered from $\mathrm{D}_{2} \mathrm{O}$-ice layer built-up during the 200 seconds exposure to the $\mathrm{D}_{2} \mathrm{O}$ beam. This variation in $\mathrm{D}_{2} \mathrm{O}$ pressure during the first 200 seconds of the experiment shows that $\mathrm{D}_{2} \mathrm{O}$ molecules are less likely to stick on $\mathrm{H}_{2} \mathrm{O}$-ice than on $\mathrm{D}_{2} \mathrm{O}$-ice. For the measurement presented in Figure 2 $\left(\mathrm{E}_{\mathrm{t}}=69 \mathrm{~kJ} / \mathrm{mol}, \theta=60^{\circ}\right)$ the difference between sticking of $\mathrm{D}_{2} \mathrm{O}$ on $\mathrm{D}_{2} \mathrm{O}$-ice and on $\mathrm{H}_{2} \mathrm{O}$-ice is about $1 \%$. This isotope effect is observed over the whole range of incident angles and translational energies covered in this study and increases with increasing incident angle and translational energy. In order to rationalize these observations, we consider Baule's formula ${ }^{16}$ 
for the sticking probability in a head-on binary collision as function of the collision partner masses $\left(\mathrm{m}_{\mathrm{g}}\right.$ and $\left.\mathrm{m}_{\mathrm{s}}\right)$,

$$
S=\frac{4 \frac{m_{g}}{m_{s}}}{\left(\frac{m_{g}}{m_{s}}+1\right)^{2}} .
$$

Equation (1) predicts a small reduction in sticking probability of $\Delta S=0.003$ for the sticking probabilities of $\mathrm{D}_{2} \mathrm{O}$ impinging on $\mathrm{H}_{2} \mathrm{O}$-ice compared to $\mathrm{D}_{2} \mathrm{O}$-ice which agrees qualitatively with the measured difference at normal incidence. However, the simple Baule model is not sufficient to describe the investigated system. It does not take into account the possible interaction of an incident molecule with several surface molecules and the coupling to lattice vibrations. In addition, it does not reproduce the increase of the isotope effect with increasing speed and larger incident angles. In contrary, the Baule formula predicts a decreasing isotope effect with larger incident angles because this model only considers momentum transfer normal to the surface. ${ }^{17}$ On the other hand, the suggestion made by Batista $e t$ al. that parallel momentum plays also a role in decreasing the water sticking cannot help to rationalize the increase in isotope effect observed here for large angles of incidence. ${ }^{4}$ In their model, the sticking probability is related to the time available for steering of the incident molecule into a favorable orientation for adsorption. Since the interaction potential of the two isotope-ices towards the incident $\mathrm{D}_{2} \mathrm{O}$ molecule should be identical, no isotope effect could arise. Application of Baule's formula shows that less efficient energy transfer due to the difference in masses of $\mathrm{H}_{2} \mathrm{O}$ and $\mathrm{D}_{2} \mathrm{O}$ molecules may play a role in the observed isotope effect. To fully account for the observed effect, we plan to perform measurements of $\mathrm{H}_{2} \mathrm{O}$ sticking on $\mathrm{H}_{2} \mathrm{O}$-ice and $\mathrm{D}_{2} \mathrm{O}$ ice. If the isotope effect is caused by the mismatch in masses between $\mathrm{H}_{2} \mathrm{O}$ and $\mathrm{D}_{2} \mathrm{O}$, one expects a higher sticking coefficient for $\mathrm{H}_{2} \mathrm{O}$ on $\mathrm{H}_{2} \mathrm{O}$-ice than $\mathrm{H}_{2} \mathrm{O}$ on $\mathrm{D}_{2} \mathrm{O}$-ice. However, if the effect is due to the higher density of phonon vibrational states for $\mathrm{D}_{2} \mathrm{O}$-ice than for $\mathrm{H}_{2} \mathrm{O}$-ice, the sticking probability of $\mathrm{H}_{2} \mathrm{O}$ might be higher on $\mathrm{D}_{2} \mathrm{O}$-ice than on $\mathrm{H}_{2} \mathrm{O}$-ice. As the phonons of hindered translations and rotations have been shown to cause the lattice isotope effects in the diffusion of helium through $\mathrm{H}_{2} \mathrm{O}$-ice and $\mathrm{D}_{2} \mathrm{O}$-ice ${ }^{18}$ they could also play a role in the sticking dynamics of water on ice.

\section{B. Insensitivity of sticking to vibrational excitation}

The previous section showed how we use the QMS signal to monitor the flux of scattered $\mathrm{D}_{2} \mathrm{O}$ molecules from the cold ice surface to obtain the $\mathrm{D}_{2} \mathrm{O}$ sticking probability by the $\mathrm{K} \& \mathrm{~W}$ method. This technique also enables us to probe for effects of vibrational excitation of the incident $\mathrm{D}_{2} \mathrm{O}$ on its sticking coefficient on ice. Figure 4 shows the scattered $\mathrm{D}_{2} \mathrm{O}$ QMS signal at $20 \mathrm{amu}$, for an incident $\mathrm{D}_{2} \mathrm{O}$ molecular beam (blue trace) of $38 \mathrm{~kJ} / \mathrm{mol}$ translational energy colliding at normal incidence with a $\mathrm{D}_{2} \mathrm{O}$ covered surface at $\mathrm{T}_{\mathrm{S}}=108 \mathrm{~K}$. Under these conditions, we measure a sticking probability of 0.995 (Figure 3). The observed pressure rise (Figure 4) when the molecular beam is admitted to the UHV chamber indicates that $99.5 \%$ of the $\mathrm{D}_{2} \mathrm{O}$ in the molecular beam is frozen out on the $\mathrm{D}_{2} \mathrm{O}$-ice surface. If vibrational excitation of the inci-



FIG. 4. $\mathrm{D}_{2} \mathrm{O}$ partial pressure rise during scattering of a $\mathrm{D}_{2} \mathrm{O}$ molecular beam $\left(\mathrm{E}_{\mathrm{t}}=38 \mathrm{~kJ} / \mathrm{mol}\right.$, normal incidence) from the $\mathrm{D}_{2} \mathrm{O}$ ice-covered surface $\left(\mathrm{T}_{\mathrm{s}}=108 \mathrm{~K}\right)$. Less than $1 \%$ of the incident $\mathrm{D}_{2} \mathrm{O}$ molecules are reflected. IR pumping of the antisymmetric OD-stretch normal mode of $25 \%$ of the incident molecules produces no detectable change in $\mathrm{D}_{2} \mathrm{O}$ partial pressure (red line indicates laser on/off).

dent $\mathrm{D}_{2} \mathrm{O}$ had an effect on the sticking coefficient, we should see a change in the scattered $\mathrm{D}_{2} \mathrm{O}$ flux upon IR pumping of the incident $\mathrm{D}_{2} \mathrm{O}$ beam. In order to maximize the signal to noise ratio for the detection of the scattered $\mathrm{D}_{2} \mathrm{O}$ flux shown in Figure 4, we used a QMS dwell time of 10 seconds. After $23 \mathrm{~min}$ of exposure of the cold surface to a molecular beam of $\mathrm{D}_{2} \mathrm{O}$ without IR pumping, an optical shutter is opened and about $1 \mathrm{~W}$ of IR radiation from the OPO is introduced into the UHV chamber to excite the molecular beam as described above. The $\mathrm{R}_{11}(1)$ transition of the antisymmetric OD-stretch of $\mathrm{D}_{2} \mathrm{O}$ is excited yielding an excited fraction of $25 \%$ of the incident $\mathrm{D}_{2} \mathrm{O}$ molecules with one quantum $\left(2787.7 \mathrm{~cm}^{-1}\right)$ of OD-stretch and $42.1 \mathrm{~cm}^{-1}(\mathrm{~J}=2)$ of rotational energy. The shutter is repeatedly opened and closed in $50 \mathrm{~s}$ intervals as shown by the red trace in Figure 4. As shown in the magnified section of Figure 4, no partial pressure changes in phase with the IR pumping are observable, which indicated that there is no detectable effect of vibrational excitation on the sticking coefficient of $\mathrm{D}_{2} \mathrm{O}$ on $\mathrm{D}_{2} \mathrm{O}$-ice under the conditions of this experiment.

From the noise of the QMS signal, we estimate an upper limit for a possible effect of ro-vibrational excitation on the sticking probability. With the rms noise of $300 \mathrm{ct} / \mathrm{s}$ and a total rise in the QMS signal of $3 \times 10^{4} \mathrm{ct} / \mathrm{s}$, we obtain an upper limit of $10^{-4}(0.01 \%)$ for the change in sticking probability. However, for the laser-on experiments, the $1 \mathrm{~mm}$ skimmer was used to increase the molecular beam flux ( $>1 \mathrm{ML} / \mathrm{s}$ ) in order to obtain better $\mathrm{S} / \mathrm{N}$ ratio for the QMS signal. Scattering of the larger molecular beam caused a negative offset of $0.7 \%$ in the measured sticking probabilities (see experimental sec- 
tion). The observed rise in $\mathrm{D}_{2} \mathrm{O}$ partial pressure corresponds to $1.2 \%$ of the $\mathrm{D}_{2} \mathrm{O}$ molecules that enter the UHV chamber but $0.7 \%$ never collided with the cold surface due to scattering at the entrance aperture. Due to this experimental artifact, the noise of $300 \mathrm{ct} / \mathrm{s}$ has to be compared to a rise of only $125000 \mathrm{ct} / \mathrm{s}$ caused by $\mathrm{D}_{2} \mathrm{O}$ scattered from the surface and consequently corresponds to a change of $2.4 \times 10^{-4}(0.024 \%)$ in sticking probability. With an excited fraction of $25 \%$, the vibrationally induced change in sticking probability must be smaller than $\Delta \mathrm{S}_{\text {Laser }}<1 \times 10^{-3}$ to show no detectable change in the QMS trace. Similar results were obtained for different incident angles between $0^{\circ}$ and $60^{\circ}$ and for $38 \mathrm{~kJ} / \mathrm{mol}$ as well as $69 \mathrm{~kJ} / \mathrm{mol}$ translational energy. In addition, no influence of ice morphology (amorphous or crystalline) could be found. This was tested by annealing the ice above crystallization temperature and cooling back down to $\mathrm{T}_{\mathrm{S}}=108 \mathrm{~K}$ before the experiment. In the case of excited $\mathrm{D}_{2} \mathrm{O}$ sticking on $\mathrm{H}_{2} \mathrm{O}$ ice an upper limit of $\Delta \mathrm{S}_{\text {Laser }}<4 \times 10^{-2}$ was found due to experimental limitations.

The insensitivity of the sticking probability to vibrational excitation for $\mathrm{D}_{2} \mathrm{O}$ on ice reported here is similar to findings of previous studies of the trapping of vibrationally excited molecules on insulator, metal and semiconductor surfaces. Gibson et al. ${ }^{6}$ reported that thermal vibrational excitation of incident $\mathrm{H}_{2} \mathrm{O}$ on $\mathrm{H}_{2} \mathrm{O}$-ice is not responsible for the fact that the sticking probability of water on ice does not reach exactly unity under the conditions of their experiments. A study of trapping of $\mathrm{NO}$ on $\mathrm{Au}(111)$ by Wodtke et al. ${ }^{19}$ found that trapping on this metal surface at $T_{S}=300$ and $480 \mathrm{~K}$ is insensitive to vibrational excitation of the incident $\mathrm{NO}$ to $\mathrm{v}=2$. For $\mathrm{Si}(100)$, Bisson et al. ${ }^{20}$ reported that the dissociative chemisorption of $\mathrm{SiH}_{4}$ on this semiconductor surface is vibrationally activated both for a direct and a precursor mediated pathway which implies that $\mathrm{SiH}$-stretch overtone excitation of $\mathrm{SiH}_{4}$ does not prevent its trapping on $\mathrm{Si}(100)$ at $\mathrm{T}_{\mathrm{S}}$ $=373 \mathrm{~K}$. These results stand in contrast to findings of Sibener and $\mathrm{Lee}^{21}$ who report that thermal vibrational excitation of $\mathrm{SF}_{6}$ and $\mathrm{CCl}_{4}$ reduces their sticking probability on their respective solid phases (amorphous ices of $\mathrm{SF}_{6}$ and $\mathrm{CCl}_{4}$ ) at low incident energy under conditions of high sticking coefficient ( $\geq 99 \%)$ similar to the conditions used here. However, the reduction of the sticking due to vibrational energy was found to be much smaller than the reduction caused by an equivalent amount of translational energy. The apparent discrepancy between the observations of Sibener and Lee and the other studies cited could be explained by a simple phenomenological model proposed by Doll ${ }^{22}$ which predicts that low frequency vibrations will have a stronger effect on the trapping probability than high frequency modes.

If the incoming molecule is to be trapped in the physisorption well, it has to transfer a sufficient amount of incident normal translational energy to the surface as indicated by the Baule equation. Damping of the incident vibrational energy is necessary for trapping only if significant mechanical coupling exists between the incident molecule's vibration and the translation degree of freedom along the surface normal (V-T coupling). Unsuccessful attempts ${ }^{23,24}$ to achieve isotope selective desorption by vibrational excitation of physisorbed molecules from insulator and metal surfaces showed that vi- bration/translation coupling is often negligible compared to the coupling to the surface modes, even for insulators such as $\mathrm{NaCl}^{23}$ The lack of isotope selectivity and the observation of a laser fluence threshold for vibrational pre-desorption were interpreted in terms of a resonant heating mechanism ${ }^{25}$ where the substrate temperature is raised due to vibrational energy transfer from internal modes of the adsorbate to surface vibrations (phonons) leading to thermal desorption. Microscopic reversibility (time-reversal) connects vibrational desorption to trapping of a vibrationally excited molecule. Therefore, both the insensitivity of trapping to vibrational excitation observed here and the lack of evidence documented in the literature for direct desorption due to resonant vibrational excitation are consistent with negligible coupling between the high frequency internal absorbate vibrations and the translation motion of the adsorbate molecule relative to the surface.

\section{SUMMARY}

In summary, measurements of the ground state sticking probability of $\mathrm{D}_{2} \mathrm{O}$ on $\mathrm{D}_{2} \mathrm{O}$-ice and on $\mathrm{H}_{2} \mathrm{O}$-ice are reported which show near unity sticking coefficients (with a $1 \%$ isotope effect), except for large angle of incidence and high incident translation energy when a significant velocity component parallel to the surface appears to reduce the trapping probability. State resolved measurements of the sticking probability of $\mathrm{D}_{2} \mathrm{O}$ on ice show that vibrational excitation of the incident $\mathrm{D}_{2} \mathrm{O}$ with one quantum of OD-stretch causes no detectable change in sticking probability $\left(<10^{-3}\right)$. It is suggested that a lack of V-T coupling in the $\mathrm{D}_{2} \mathrm{O}$ surface scattering is responsible for the insensitivity of trapping to vibrational excitation.

\section{ACKNOWLEDGMENTS}

We gratefully acknowledge financial support provided by the Swiss National Science Foundation (Grant No. 134709/1) and the Ecole Polytechnique Fédérale de Lausanne as well as helpful discussions with Bruce Kay and Andrew Hodgson.

${ }^{1}$ O. B. Toon, R. P. Turco, J. Jordan, J. Goodman, and G. Ferry, J. Geophys. Res., [Atmos.] 94(D9), 11359-11380, doi:10.1029/JD094iD09p11359 (1989).

${ }^{2}$ C. Dijkstra, C. Dominik, S. N. Hoogzaad, A. de Koter, and M. Min, Astron. Astrophys. 401(2), 599-611 (2003).

${ }^{3}$ M. Jura and M. Morris, Astrophys. J. 292(2), 487-493 (1985).

${ }^{4}$ E. R. Batista, P. Ayotte, A. Bilic, B. D. Kay, and H. Jonsson, Phys. Rev. Lett. 95(22), 223201 (2005).

${ }^{5}$ D. E. Brown, S. M. George, C. Huang, E. K. L. Wong, K. B. Rider, R. S. Smith, and B. D. Kay, J. Phys. Chem. 100(12), 4988-4995 (1996).

${ }^{6}$ K. D. Gibson, D. R. Killelea, H. Q. Yuan, J. S. Becker, and S. J. Sibener, J. Chem. Phys. 134(3), 034703 (2011).

${ }^{7}$ M. P. Schmid, P. Maroni, R. D. Beck, and T. R. Rizzo, Rev. Sci. Instrum. 74(9), 4110-4120 (2003).

${ }^{8}$ B. L. Yoder, R. Bisson, and R. D. Beck, Science. 329(5991), 553-556 (2010).

${ }^{9}$ B. L. Yoder, R. Bisson, P. M. Hundt, and R. D. Beck, J. Chem. Phys. 135(22), 224703 (2011).

${ }^{10} \mathrm{~N}$. Matsunaga and A. Nagashima, Int. J. Thermophys. 8(6), 681-694 (1987).

${ }^{11}$ S. V. Shirin, N. F. Zobov, and O. L. Polyansky, J. Quant. Spectrosc. Radiat. Transfer. 109(4), 549-558 (2008).

${ }^{12}$ D. A. King and M. G. Wells, Surf. Sci. 29(2), 454-482 (1972).

${ }^{13}$ N. V. Vitanov, T. Halfmann, B. W. Shore, and K. Bergmann, Ann. Rev. Phys. Chem. 52, 763-809 (2001).

${ }^{14}$ M. E. Gallagher, S. Haq, A. Omer, and A. Hodgson, Surf. Sci. 601(1), 268-273 (2007). 
${ }^{15}$ R. S. Smith, J. Matthiesen, J. Knox, and B. D. Kay, J. Phys. Chem. A. 115(23), 5908-5917 (2011).

${ }^{16}$ R. I. Masel, Principles of Adsorption and Reaction on Solid Surfaces (Wiley, New York, 1996).

${ }^{17}$ E. K. Grimmelmann, J. C. Tully, and M. J. Cardillo, J. Chem. Phys. 72(2), 1039-1043 (1980).

${ }^{18}$ J. L. Daschbach, G. K. Schenter, P. Ayotte, R. S. Smith, and B. D. Kay, Phys. Rev. Lett. 92(19), 198306 (2004).

${ }^{19}$ A. M. Wodtke, H. Yuhui, and D. J. Auerbach, Chem. Phys. Lett. 413(4-6), 326-330 (2005).
${ }^{20}$ R. Bisson, T. T. Dang, M. Sacchi, and R. D. Beck, J. Chem. Phys. 129(8), 081103 (2008).

${ }^{21}$ S. J. Sibener and Y. T. Lee, J. Chem. Phys. 101(2), 1693-1703 (1994).

${ }^{22}$ J. D. Doll, J. Chem. Phys. 66(12), 5709 (1977).

${ }^{23}$ B. Redlich, H. Zacharias, G. Meijer, and G. von Helden, J. Chem. Phys. 124(4), 044704 (2006).

${ }^{24}$ I. Hussla, H. Seki, T. J. Chuang, Z. W. Gortel, H. J. Kreuzer, and P. Piercy, Phys. Rev. B. 32(6), 3489 (1985).

${ }^{25}$ Z. W. Gortel, H. J. Kreuzer, P. Piercy, and R. Teshima, Phys. Rev. B. 28, 2119 (1983) 